\title{
A Comparative Study of Chinese Art Market and Western Art Market
}

\author{
Hua Li \\ Southeast University, Nanjing, Jiangsu, China
}

\begin{abstract}
The art market is becoming more and more active with the rapid development of China's economy. The art market is generally divided into primary market and secondary market. Compared with the more mature primary and secondary markets of foreign artworks, there is a considerable degree of confusion and in line with the uniqueness of national conditions in China's art trade in the process of marketization. The modern Chinese art market operates on Western art market as a reference. The Western art market has become mature over the centuries and has accumulated a wealth of experience. In the initial stage of China, there is much to learn from the western art market. In the era of knowledge economy, under the background of the globalization of the world economy, it is a task that everyone must face to strengthen the economic and cultural exchanges and cooperation between countries.
\end{abstract}

Keywords: Art market, Primary market, Secondary market.

\section{Current Situation of Chinese Art Market}

Since the reform and opening-up, China's achievements in economic construction have attracted worldwide attention. With the rapid development of the market economy and the further deepening of the reform of the cultural system, artworks are gradually penetrating into people's daily lives in a unique industrial development mode, and the art market has become another investment hotspot after stocks and real estate.

In the context of excessive financial liquidity, rising inflationary expectations, and the art market's gradual transition to an investment-oriented market, the domestic art market is dominated by capital investors who simply treat art as a general commodity and pursue the maximization of capital gains by means of speculation. The price of artwork is highly deviated from its value. Under the condition of modern market economy, artists place the pursuit of commercial value over artistic value, and the creative motives and impulses are more to cater to the market and collectors' tastes, which makes the target marketing of today's art market appear so strikingly unified.

Another feature of the Chinese art market is the serious misalignment between the primary and secondary markets. Galleries and auction houses are supposed to play their respective roles in a mature and well-developed art market structure. Due to the dislocation of the domestic art market, the people are unable to recognize the fine artworks recognized by the secondary market, even if the "sky-high" works are also mixed praise and criticism, lacking widespread social recognition, forming a group of well-known and famous painters like "shooting stars", which not only makes the industry Chaos, but also makes the entire industry to form a reliable credibility, so that the development of the entire art market overshadowed.

\section{Current Situation of the Western Art Market}

The Western art market originated in the Renaissance, and the cultural art collection market was influenced by this movement, which made it prosperous. The Renaissance saw the emergence of artists' guilds, which played a role similar to that of a middleman in the sale of artworks, introducing buyers to artists while extracting commissions and dues from them. As the era progressed, galleries and museums were established, and the primary market gallery was transformed from a place for private collection to a public place for the display of artworks. The development of the Western capitalist economy has promoted the development of the art market. In the late nineteenth century, the gallery industry in the West developed rapidly after World War II, and the primary market gallery industry had become the most important channel for artists and artworks to enter the market.

The rapid development of the auction market in the West contributed to the prosperity of the secondary art market. After the Second World War, economic recovery and development, Western art auction houses sprang up. Sotheby's and Christie's, founded in the eighteenth century, account for a large share of the international art market, accounting for 30 to 40 percent of the total. They have been the most influential international auction houses for nearly two centuries. Especially during the high economic growth of the 1980s, the cultural and artistic sector became a desirable investment.

Western art fairs flourished. Western art fair is a major part of the art market's operating mechanism, is an important place for artists and galleries to showcase themselves and promote the circulation of art. During the Second World War, the European economy boomed, promoting the beginning of the consumer market in the cultural era. The number of artists, primary market galleries and collectors involved in the event was unmatched by primary market galleries and auction houses. It not only promoted the development of the art market, but also promoted the construction of the cultural image of the city. 


\section{One of the Differences between the Chinese and Western Art Markets: The Order of the Market}

Research on the issue of "secondary market overstepping" has a long-time span. In the mature Western art market standards, the gallery industry is the primary market representative; the auction industry is the secondary market representative. Artworks must be authenticated and vetted by the primary market before entering the secondary market. For example, the art auction law of Germany in Europe stipulates that only artworks by artists who have passed away or works by the world's most recognized artists are allowed to be auctioned.

Western contemporary artists enter the art market through the path of primary market galleries - as their popularity, influence and other factors increase to enter art collection institutions or art galleries, museums, etc. - see important competitions or art fairs, etc. -- and finally can enter the secondary market auction market. But currently in China, many unknown painters enter the auction market directly, and sometimes they fetch "sky-high" prices, which has an extremely bad impact on the whole art market. The emergence of this phenomenon also has the current domestic social environment and other important factors.

Therefore, with the rapid development of the art market, part of the regulations and policies have not been introduced, some artists, brokers, capital operators are impatient to invest in it. The operation of capital has become the theme, part of the price of art and the intrinsic value of a serious disconnect. Some unnamed young artists have become the creators of "sky-high" auction works, which is not only the main reason for the imperfection of the art market mechanism, but also the objective factor of the lack of supervision of the social environment of capital operation. Such a development has led to the primary market of the gallery industry, long-term failure to assume its own function, and with the secondary market auction industry flourished, and gradually by the market diluted.

\section{The Second Difference between Chinese and Western Art Markets: The "Absence" of Galleries}

Compared with the gallery industry in developed countries in the West, the overall level of the domestic gallery industry should still be in its infancy. Domestic gallery industry has always been in the antique sales, sales of painting materials, art post-processing and other sales-type primary stage, which did not form the corresponding standardized scientific industry system. Because Chinese art market developed suddenly after a long period of depression, many gallery operators did not have time to figure out what is art, the primary market of the gallery and what, and a series of questions into the market. Not to mention having a clear art concept, a high artistic taste as well as artistic guidance and long-term planning. They just regard the art market as a pure commercial shopping mall. How to develop cultural ideas and nurture and support young painters are not in their scope of thinking. Even in Beijing, some of the more established galleries only deal with the works of some of the more famous artists of the modern era.

In addition, many Chinese collectors are "entrepreneurs" or "individual business operators" who have become rich first, lacking the corresponding artistic heritage, and the purpose of art collection is not for art appreciation, but for capital profit of artworks. Therefore, when collecting, they do not consider their own art appreciation and aesthetic vision, but set on the market recognition of well-known artists, from the secondary market auction industry in the sense of fire, it is easy to judge that the work has a high degree of social recognition.

The key to the maturity of the art market depends on the maturity of the gallery industry in the primary market. In China, although the number of galleries in the primary market is in the thousands, there are only a dozen galleries recognized by the industry, most of which can only be called painting stores and painting stalls. In the whole art market in the scope of the primary market, the gallery contains orphans operators, producers, collectors are not concerned about the primary market system and functional integrity, blind participation in the social boom, making the entire art market is like a "pavilion in the air", the primary market should be strong to become "Weak area", so how to cultivate the primary art market (gallery industry) to adapt to Chinese society, still need to explore in depth.

\section{Implications for the Development of China's Art Market}

Today, in the 21 st century, the prosperity of the art market has led to the gradual development of the producers and various types of enterprises dependent on its existence into a closely related industry of the national economy. Compared with commodity trading in ancient and modern times, it has far exceeded the scope of professions and industries. The art market is a carrier of cultural and economic symbiosis, and the prosperity and healthy development of the art market is not only conducive to the development of a country's economy, but also to the transmission and dissemination of a country's culture, and to the promotion of a country's soft power. In view of the dislocation of the Chinese art market and its highly divergent value phenomenon, we should start from both market regulation and market construction, so that the price of Chinese art can get rational return.

On the market system. Against the backdrop of a hot domestic art market, the art market is driven by the interest of huge profit returns, speculation, counterfeiting, and underhand operations. Here there is certainly weak regulation of the art market, unable to ensure the reasonable operation of the market order, but also the main cause of the lack of a fair competition mechanism within the general environment. In the late 1990 s, the country also promulgated a number of laws and regulations, but from the current state of affairs, there is still a need for further enrichment and improvement. In particular, there is a need to strengthen the credit system of the 
art market and increase the transparency of the art market. In short, a relatively sound art market mechanism should be formed, including the construction of the system, credibility, legal construction, development strategies and the construction of service mechanisms, which is the key to the maturity of the Chinese art market.

About the market construction. Chinese art market has developed to the point where the primary market is sluggish, and the secondary market is thriving in a perverse way. The prosperity of an art market should be the joint prosperity of the primary market and the secondary market is the real prosperity. An important reason for the prominence of such problems lies in the absence of China's art identification system, the lack of a strong and effective and authoritative national level art identification system, resulting in the failure to produce industry recognition standards. Therefore, it is necessary to strengthen the relevant soft environment construction issues, improve the quality of national culture and art, improve the academic system of market evaluation, and make the art market mechanism more perfect, so that the various functions of the art market really play a role in the overall improvement of the quality of culture and art for all. Government cultural management departments at all levels, the media and professional institutions must make correct use of various public opinion media, adhere to the correct orientation, create a rational collection and investment atmosphere in society as a whole, and guide the art market toward a healthy and orderly development in a benign direction.

\section{References}

[1] Arnold Hauser. Sociology of Art [M]. Shanghai: Xuelin Publishing House, 1987.

[2] Du Dakai, editor-in-chief. Tsinghua Fine Arts Volume 8Chinese Contemporary Art and Capital [M]. Beijing: Tsinghua University Press, 2008.

[3] Gu Zhaogui. Introduction to Art Economics [M]. Beijing: Culture and Art Publishing House, 2004.

[4] He Qing. Conspiracy of Art [M]. Nanning: Guangxi Normal University Press, 2008.

[5] Written by Lumber, translated by Hongjun Zhong. Auction Theory and Practice [M]. Beijing: China Renmin University Press, 2006.

[6] $\mathrm{Li}$ Wankang. Introduction to Art Marketing [M]. Shanghai: Fudan University Press, 2005.

[7] Li Xiangmin. The History of Chinese Art Economy [M]. Nanjing: Jiangsu Education Press, 1995.

[8] Lin Rikui. Art Economics [M]. Beijing: China Business Press, 2006.

[9] Lin Rikui. Art Pawn and Auction [M]. Hangzhou: Zhejiang Gongshang University Press, 2009.

[10] Edited by Lu Xianxiang and Lu Qiaoling. New Institutional Economics. Beijing: Peking University Press, 2007.

[11] Luo Bing. International Art Trade [M]. Beijing: Communication University of China Press, 2009.

[12] Ma Feicheng, Jing Jipeng. Analysis of Information Economy [M]. Beijing: Science and Technology Academic Press, 2005.
[13] Ma Jian. Economics of art Market - Devil and Angel of art Market [M]. Beijing: China Times Economics Press, 2008.

[14] Qin Chunrong, editor-in-chief. Art Investment [M]. Shanghai: Shanghai University Press, 2005.

[15] Wu Mingdi, editor. Research on Art Market [M]. Beijing: Capital Normal University Press, 2010.

[16] Xi Mu. Research on Theory and Practice of Chinese Art Share Transaction [M]. Beijing: China Bookstore, 2011.

[17] Xi Mu. Annual Research Report of Chinese Art Market (2008) [M]. Beijing: China Bookstore, 2009.

[18] Xie Luncan. Art Industry Operation [M]. Beijing: People's Publishing House, 2007.

[19] Zhao Li (Ed.). 2008-2009 Chinese Art Market Research Report [M]. Changsha: Hunan Fine Arts Publishing House, 2009.

[20] Art Market Analysis Center, Central Academy of Fine Arts[M]. Changsha: Hunan Fine Arts Publishing House, 2006. 